University of Nebraska - Lincoln

DigitalCommons@University of Nebraska - Lincoln

$9-2009$

\title{
Experiencing Rare and Unusual Events Richly: The Role of Middle Managers in Animating and Guiding Organizational Interpretation
}

Tammy E. Beck

University of North Carolina at Charlotte, tbeck8@unl.edu

Donde Ashmos Plowman

University of Nebraska-Lincoln, dplowman2@unl.edu

Follow this and additional works at: https://digitalcommons.unl.edu/managementfacpub

Part of the Management Sciences and Quantitative Methods Commons

Beck, Tammy E. and Plowman, Donde Ashmos, "Experiencing Rare and Unusual Events Richly: The Role of Middle Managers in Animating and Guiding Organizational Interpretation" (2009). Management Department Faculty Publications. 61.

https://digitalcommons.unl.edu/managementfacpub/61

This Article is brought to you for free and open access by the Management Department at DigitalCommons@University of Nebraska - Lincoln. It has been accepted for inclusion in Management Department Faculty Publications by an authorized administrator of DigitalCommons@University of Nebraska - Lincoln. 


\title{
Experiencing Rare and Unusual Events Richly: The Role of Middle Managers in Animating and Guiding Organizational Interpretation
}

\author{
Tammy E. Beck \\ Department of Management, University of North Carolina at Charlotte, Charlotte, North Carolina 28223, \\ tammy.beck@uncc.edu \\ Donde Ashmos Plowman \\ Department of Management, College of Business, University of Tennessee, Knoxville, Tennessee 37996, \\ dplowman@utk.edu
}

\begin{abstract}
$\mathrm{O}$ rganizations have difficulty learning from rare and unusual events because of their inability to interpret these events. Because organizations develop habitual ways of interpreting events—often top down — they can easily miss the novelty of rare and unusual events, which prevents them from experiencing events "richly." We propose a multilevel, multistaged model of organizational interpretation that highlights the important, but generally unacknowledged, role middle managers can play in helping organizations experience rare and unusual events richly. Our model accounts for the effect of cognitive biases and hierarchical context on organizational interpretation. Because of their proximity to the interpretations of both strategic and front-line managers, middle managers can encourage divergence in interpretations of managers across hierarchical levels during early stages of the interpretation process and can blend and synthesize the divergent interpretations of managers during later stages. In this way middle managers contribute to a dynamic process of organizational interpretation in which multiple filters from throughout the organization help frame and enrich interpretations of rare and unusual events, which enables organizational learning.
\end{abstract}

Key words: organizational interpretation; middle managers; organizational learning

History: Published online in Articles in Advance June 10, 2009.

If history repeats itself, and the unexpected always happens, how incapable must Man be of learning from experience. (George Bernard Shaw 1903)

Research suggests that organizational success depends on learning to predict, detect, and deal with rare and unusual events (Ansoff 1975, Cunha et al. 2006, Lampel and Shapira 2001, Watkins and Bazerman 2003). However, studies show that behavioral and organizational habits "make it difficult to 'see' what is right in front of one's face" (Day and Schoemaker 2004, p. 137). Organizations have difficulty learning from rare and unusual events because of their inability to interpret these events; they rely on "habitual ways of thinking and perceiving" (Senge et al. 2004, p. 29), missing the novelty of the event. In this paper, we argue that effective learning from rare and unusual events, although difficult, can occur if decision makers develop the ability to perceive and experience events "richly." This ability requires expanding the number and diversity of interpretations of rare and unusual events as they happen (March et al. 1991).

Traditionally, organizational scholars have viewed the interpretation process as primarily the responsibility of top managers, leaving the rest of the organization to implement appropriate actions. But in this paper we argue that contrary to that view, middle managers play a crucial and hitherto neglected role in enriching the experience and interpretation of rare and unusual events because they are the "hub through which most strategic information flows" (Floyd and Lane 2000, p. 164). Middle managers can facilitate divergence of interpretation in early stages of organizational interpretation by surfacing conflicting views-and convergence in later stages of interpretation by synthesizing disparate views. Both divergence and convergence play an important part in learning from rare and unusual events and in strategic choices (Park 2007). Divergent thinking early in the recognition of a rare and unusual event encourages multiple ways of interpreting and viewing the event. Convergence, in contrast, enables action and adaptation. Thus, organizations increase their capacity to learn from rare and unusual events when they resist an exclusively top-down approach to interpretation and instead solicit the participation of middle managers during both the early phases and subsequent process of interpretation and analysis.

We develop our key arguments by drawing primarily from the literature on organizational interpretation, with additional insights borrowed from research on rare and unusual events and organizational learning. We focus on three essential dimensions of organizational interpretation - temporal, cognitive, and hierarchical. We show that interpretation occurs in stages (Isabella 1990), with each stage being influenced by cognitive biases and 
hierarchical context. We then use examples from the space shuttle Columbia disaster ${ }^{1}$ to show how the lack of meaningful middle manager involvement at each stage of the disaster interpretation may have impeded organizational learning. We use this counterpoint example to explore middle management behaviors that enable organizations to experience rare and unusual events more richly, thereby enhancing organizational learning. We conclude with a discussion of the contributions, limitations, and implications of our model.

\section{Dealing with Rare and Unusual Events}

Rare and unusual events can originate both from within (Isabella 1990) and from outside the organization (Barr 1998). Such events can take many forms: strategic surprises (Cunha et al. 2006, Lampel and Shapira 2001), environmental jolts (Meyer 1982), and major change events (Brown and Humphreys 2003). By definition, rare and unusual events occur infrequently and thus present unique learning challenges because of organizations' lack of direct experience. Lack of direct experience forces people to search for ways to understand such events by creating interpretations and narratives that can reduce the associated ambiguity (Abma 2000, Cunha et al. 2006). In the case of rare and unusual events, the existing narratives typically fail to provide interpretations that organizational members regard as meaningful or satisfactory. This in turn leads individuals to search for new interpretations, not to mention creating new stories, that better account for the origins and impact of the events. More generally, repeated exposure to rare and unusual events often induces an ongoing process of organizational sensemaking through narratives and interpretation that is itself an important skill (Czarniawska 1998).

Generally, organizational scholars have addressed rare and unusual events in one of three ways. First, some scholars have focused on the importance of trying to detect, predict, and avoid such events (Ansoff 1975, Kauffman 1995, Lampel and Shapira 2001, Watkins and Bazerman 2003, Wissema 2002). Others have focused on how managers deal with such events by socially constructing their environments, selectively perceiving some cues and ignoring others, and then enacting what gets labeled as a surprise or a crisis (Lant et al. 1992, Mezias and Starbuck 2003, Nystrom and Starbuck 1984, Weick 1995). Finally, complexity scholars have begun to view organizations as unpredictable complex social systems (Kauffman 1995, Levy 1994) in which rare and unusual events emerge from unexpected places (Balogun 2006, Plowman et al. 2007). Novelty and surprise are pervasive and unavoidable features of these complex social systems (Cunha et al. 2006, McDaniel et al. 2003), and they often require unique organizational responses (Majchrzak et al. 2007).
In all cases, noticing and extracting salient cues represent the first steps an organization must take to make some sense of rare and unusual events. The cues that get noticed and extracted are the ones that get enhanced with meaning and interpretations (Weick 1995), which is how the organization learns. How, then, do organizations interpret and make sense of rare and unusual events to learn from them? How do organizations avoid looking at today's events through tired perceptual lenses? Focusing on top managers as the sole interpreters of such events ignores the reality that organizations consist of many managers, each of whom must create their own individual interpretation of each particular event. Each interpretation likely helps shape the interpretations of others up, down, and across the hierarchy and contributes to what the organization learns.

Our central argument is that the interpretation of rare and unusual events occurs at all levels of the organization and that at each level cognitive heuristics affect interpretations and contribute to conflicting understandings. Our model suggests that when middle managers actively participate during all stages of the interpretation process, organizations are less likely to make mistakes and more likely to use richer interpretations, which enhance their learning from rare and unusual events.

\section{Issues with Organizational Learning}

Three basic ideas from the organizational learning literature inform the discussion about interpretation and learning from rare and unusual events: (1) organizations learn in stages, (2) organizations learn from experience (Huber 1991, Senge 1990), and (3) organizations learn from small samples by experiencing history richly. Each of these ideas has unique importance when the event facing the organization is rare and unusual.

\section{Organizations Learn in Stages}

The stages of scanning, interpretation, action, and learning/readjustment characterize most models of learning (e.g., Daft and Weick 1984, Day and Schoemaker 2004). In the scanning stage, organizations collect data; in the interpretation stage, they give meaning to data. In the action stage of learning, organizations decide and respond; and in the learning/readjustment stage, they obtain feedback and readjust. Thus, our attention to how organizations interpret unusual events (the second stage of learning) informs the conversation about how organizations learn from those events.

\section{Organizations Learn from Direct Experience}

Perhaps the most profound learning for either individuals or organizations comes from direct experience. For example, a person or organization takes an action, and on seeing the consequence of the action takes a different action. 
However, learning from experience is difficult for organizations for several reasons. First, individuals are imperfect processors of information (Hogarth 1987) and "as sensors of experience, function imperfectly" (Huber 1991, p. 95). Second, people often have competing interpretations of what past experiences mean (Levitt and March 1988). Finally, organizational members may not be able to assess the consequences of many of their decisions because these can sometimes take years to fully unfold (Senge 1990). For example, the full implications of a strategic decision to acquire a competitor are often not fully known for years, long after the actual decision makers may be gone. In the case of rare and unusual events, experience as a teacher is even more limited, because organizations most likely have not experienced such an event before.

\section{Organizations Learn from Small Samples}

Rare and unusual events are by definition "small samples," but as March and colleagues argue, organizations can learn from small samples by "experiencing history richly" (1991, p. 2). March and colleagues suggest this happens in three ways. First, organizations can learn more effectively when they are able to experience more aspects of the event as they are responding to it, even as the event is occurring. The organization is able to do this when its members actively engage in asking questions. What does this event mean today? What will it mean tomorrow? What does the organization's response mean? How does the organization's response change what we believe? If organizations encourage this kind of ongoing sensemaking as the event and the organization's response unfold rather than after the fact, the organization "learns as it goes." Learning then occurs from experiencing the event, rather than merely from the consequences following the event.

A second way organizations experience rare and unusual events richly, according to March and colleagues (1991), is to experience more interpretations from more and different people. Individuals may learn different lessons when confronted with the same incident. Other learning scholars have also argued that learning is enhanced when there is a focus on multilevel information sources (Schwab 2007), when there are more interpretations (e.g., Huber 1991, March et al. 1991), and when there is diversity in interpretations (Fiol 1994, Rothman and Friedman 2001). For example, Huber (1991, p. 102) states that "more learning has occurred when more and more varied interpretations have been developed, because such development changes the range of the organization's potential behaviors." When organizations seek out multiple interpretations of unusual events from multiple organizational members, the chances of creating a "mosaic of conflicting lessons" (March et al. 1991, p. 3) increases.
The third way organizations experience rare and unusual events richly is by experiencing different preferences for the outcomes of an event (March et al. 1991). Yet as March and his colleagues point out, the impact of an event's outcomes is not self-evident. People differ in their assessments of outcomes and in their preferences for one outcome over another. When the differences in how organizational members assess events and their outcomes are visible, "organizations learn what they are" (March et al. 1991, p. 3). How an organization assesses the impact of rare and unusual events depends in part on what the firm values, its aspirations, and its identity. Thus, organizations learn from rare and unusual events when they experience and consider a broad set of aspirations or preferences for outcomes.

The discussion of March and colleagues (1991) of learning from small samples by experiencing events richly theoretically grounds the model of interpretation developed in this paper. Organizations learn from rare and unusual events when multiple players experience the event as it unfolds, when multiple interpretations of the event receive attention, and when the preferences for assessing the event's outcomes come from multiple players. In sum, a key to learning from rare and unusual events is to experience them richly by encouraging multiple voices, perspectives, and interpretations.

\section{Issues with Organizational Interpretation}

Rare and unusual events require rich interpretation, yet the interpretation literature has been somewhat narrowly focused on how top managers influence how others understand issues (Dutton and Jackson 1987, Gioia and Thomas 1996, Maitlis 2005) and to what degree top managers' interpretations influence organizational outcomes (Thomas et al. 1993, Thomas and McDaniel 1990). Interpretation is the process of assigning meaning to events, and two decades worth of research asserts that organizations function as interpretation systems (Daft and Weick 1984). Managers make sense of their environments by interpreting events (Weick 1993, 1995), and this sensemaking forms the basis for organizational actions, adaptation, and performance (Barr 1998, Thomas et al. 1993). Organizational interpretation is the collective result of what is essentially an individual's experience. Organizational interpretation is a shared unit property (Klein and Kozlowski 2000). It originates in the individual unit members' interpretations, yet converges among organizational members because of unit members' daily interactions.

The interpretation literature suggests at least two notions about organizational interpretation that are relevant to rare and unusual events. First, most studies of organizational interpretation take an "upper echelon" view, drawing primarily on CEO accounts to represent the organization's view. This notion of organizational 
interpretation led scholars to identify variables that affect top managers' thinking, such as top-management-team experiences, backgrounds, and information processing capacity (Golden et al. 2000, Milliken 1990, Thomas et al. 1993, Thomas and McDaniel 1990, Thomas et al. 1994). Although many scholars acknowledge the existence of multiple interpretations within organizations (Brooks 1997, Lant et al. 1992, Martins and Kambil 1999, Sharma 2000), the majority of research focuses on multiple interpretations within the same strategic level. Assigning responsibility for organizational interpretation solely to top management means that cues or signals detected by lower-level managers can be disregarded by those at higher levels, limiting what the organization learns from unfolding events. In the case of rare and unusual events, relying solely on top management interpretations limits the likelihood that the organization will experience events richly.

A second notion from the interpretation literature is that interpretation is considered a process that occurs in stages (Daft and Weick 1984, Meyer 1982, Milliken 1990, Thomas et al. 1993), regardless of the event encountered. What we know, empirically, about the process of interpretation has come largely from the studies of Isabella (1990) and Barr (1998), who both observed that interpretation of top managers evolves in distinct stages. If, in fact, interpretation occurs in unique stages, then what comes to be known as "unusual" or "rare" evolves over time.

Although the interpretation literature advanced our knowledge of organization-level interpretation and the social construction of meaning, there has been little consideration of the role of middle managers in forming an organization's interpretation and scant attention to their role in how the organization interprets and learns from rare and unusual events. Middle managers are individuals who make decisions about how to implement the organization's strategic objectives. They operate at the intermediate level of the organizational hierarchy, two or three levels below the CEO (Dutton and Ashford 1993, Wooldridge and Floyd 1990); they supervise supervisors and are supervised by others (Dutton and Ashford 1993). Middle managers interpret information and knowledge from top managers to make it meaningful to those below them in the hierarchy who are responsible for technical activities. At the same time they interpret information and knowledge from functional managers about technical and day-to-day realities of the organization (Dutton and Ashford 1993). They then select those pieces of information that need top management attention. Thus, middle managers are responsible for interactions with those above them, with those they supervise, and with their peers. As Floyd and Lane note, "The complexity of information and number of potential interactions, therefore, are greater for middle managers than for top or operating-level managers" (Floyd and Lane 2000, pp. 164-165).

Middle managers' pivotal position in the hierarchy allows them to play a critical role in interpreting events, creating meaning, and directing the attention of the organization (Dutton et al. 1997, Huy 2002, Sims 2003, Van Cauwenbergh and Cool 1982). Nonaka $(1988,1994)$ notes the importance of middle managers in creating knowledge because they are at the intersection of the vertical and horizontal flows of information. This is where the tacit knowledge (personal, difficult to formalize) of the strategic levels becomes explicit knowledge (codified and transmittable) for the front-line levels and where the tacit knowledge of front-line managers becomes explicit for strategic managers. Similarly, Balogun and Johnson (2004) observed that middle managers help resolve cognitive disorder and therefore play a significant role in the sensemaking process.

Moreover, middle managers use their own tacit knowledge to help those above and beneath them "make sense" of events (Rouleau 2005). Middle managers can help organizations experience rare and unusual events richly because they likely see more and different aspects of a rare and unusual event than either top-level or front -line managers. By virtue of their position in the organization and their ongoing interactions, middle managers have access to multiple and sometimes conflicting interpretations of others throughout the organization. We now turn to this process of interpretation.

\section{Temporal, Cognitive, and Hierarchical Dimensions of Interpretation}

Organizations form interpretations of rare and unusual events to reduce ambiguity and also to learn how to deal with such events in the future. However, organizational members do not create interpretations of these events all at once; interpretations usually form in stages (Barr 1998, Isabella 1990). Further, individuals are not perfect information processors (Hogarth 1987, Simon 1947). At each stage of the process, cognitive heuristics affect interpretations (Hodgkinson and Sparrow 2002, Hogarth 1987, Schwenk 1984). Finally, organizational members at all levels of the organization form their own interpretations of such events. These individual interpretations are heavily influenced by the position of each individual within the organizational hierarchy.

\section{Temporal Sequence and Interpretation of Rare Events}

Isabella (1990) observed a temporal dimension to interpretation, that is, it occurs in four distinct stages (see Table 1): anticipation, confirmation, culmination, and aftermath. The Anticipation Stage is comprised of the rumors, speculations, and fragments of disjointed bits of information regarding the event under consideration. 
Table 1 Multilevel Multistaged Model of Organizational Interpretation for Rare and Unusual Events

\begin{tabular}{|c|c|c|c|c|}
\hline Stages of interpretation & $\begin{array}{l}\text { Anticipation: } \\
\text { Interpretation of rare } \\
\text { event is composed } \\
\text { of rumors and tidbits } \\
\text { of information or } \\
\text { speculation that an } \\
\text { event may happen. }\end{array}$ & $\begin{array}{l}\text { Confirmation: } \\
\text { Interpretation of rare } \\
\text { event is an explanation } \\
\text { of what will happen } \\
\text { based on what has } \\
\text { happened before, also } \\
\text { what the event will } \\
\text { mean personally. }\end{array}$ & $\begin{array}{l}\text { Culmination: Interpretation } \\
\text { of rare event is an } \\
\text { amended explanation } \\
\text { based on the event in } \\
\text { progress, including } \\
\text { images of before and } \\
\text { after. }\end{array}$ & $\begin{array}{l}\text { Aftermath: Interpretation } \\
\text { of rare event is an } \\
\text { evaluation now that the } \\
\text { event has occurred, } \\
\text { including strengths and } \\
\text { weaknesses, winners } \\
\text { and losers. }\end{array}$ \\
\hline $\begin{array}{l}\text { Cognitive biases likely to } \\
\text { affect each stage }\end{array}$ & $\begin{array}{l}\text { - Selective perception } \\
\text {-Frequency } \\
\text {-Illusory correlation }\end{array}$ & $\begin{array}{l}\text {-Availability bias } \\
\text { —Representativeness } \\
\text { —Anchoring and } \\
\text { adjusting }\end{array}$ & $\begin{array}{l}\text { —Framing } \\
\text { —Illusion of control } \\
\text {-Wishful thinking }\end{array}$ & $\begin{array}{l}\text { - Hindsight bias } \\
\text { —Fallacies in recall } \\
\text { —Attribution bias }\end{array}$ \\
\hline $\begin{array}{l}\text { Strategic managers' } \\
\text { interpretation }\end{array}$ & $\begin{array}{l}\text { Assemble rumors of } \\
\text { possible rare event } \\
\text { that are consistent } \\
\text { with strategic } \\
\text { assumptions and } \\
\text { beliefs. }\end{array}$ & $\begin{array}{l}\text { Develop explanations of } \\
\text { rare event based on } \\
\text { previous strategic } \\
\text { experiences. }\end{array}$ & $\begin{array}{l}\text { Amend earlier explanation } \\
\text { of rare event, reducing } \\
\text { gap between strategic } \\
\text { expectations and } \\
\text { strategic realities. }\end{array}$ & $\begin{array}{l}\text { Develop strategic } \\
\text { evaluations and } \\
\text { assessments of } \\
\text { strategic winners and } \\
\text { losers from rare event. }\end{array}$ \\
\hline $\begin{array}{l}\text { Front-line managers' } \\
\text { interpretations }\end{array}$ & $\begin{array}{l}\text { Assemble rumors of } \\
\text { rare event that are } \\
\text { consistent with } \\
\text { operational/technical } \\
\text { assumptions and } \\
\text { beliefs. }\end{array}$ & $\begin{array}{l}\text { Develop explanations of } \\
\text { rare event based on } \\
\text { previous operational } \\
\text { experiences. }\end{array}$ & $\begin{array}{l}\text { Amend earlier explanation } \\
\text { of rare event, reducing } \\
\text { gap between } \\
\text { operational } \\
\text { expectations and } \\
\text { operational realities. }\end{array}$ & $\begin{array}{l}\text { Develop operational } \\
\text { evaluations and } \\
\text { assessments of } \\
\text { operational winners } \\
\text { and losers from rare } \\
\text { event. }\end{array}$ \\
\hline $\begin{array}{l}\text { Middle managers' role } \\
\text { Balance activity to } \\
\text { disseminate and } \\
\text { synthesize } \\
\text { interpretations of } \\
\text { strategic and } \\
\text { front-line managers } \\
\text { with that of other } \\
\text { middle managers. }\end{array}$ & $\begin{array}{l}\text { Surface conflicting } \\
\text { rumors, and elicit } \\
\text { exposure of } \\
\text { information tidbits } \\
\text { from multiple } \\
\text { sources. }\end{array}$ & $\begin{array}{l}\text { Facilitate the exchange } \\
\text { of explanations of rare } \\
\text { event that come from } \\
\text { numerous sources. }\end{array}$ & $\begin{array}{l}\text { Blend amended } \\
\text { explanations of rare } \\
\text { event received from } \\
\text { others in the } \\
\text { organization. }\end{array}$ & $\begin{array}{l}\text { Synthesize the strategic } \\
\text { evaluations with } \\
\text { operational } \\
\text { evaluations of rare } \\
\text { event. }\end{array}$ \\
\hline
\end{tabular}

Confirmation is the stage where comparisons are made to similar and/or different past events and provide parallel frames of reference. Once additional information is available, interpretations adjust to match the reality of the event and thus reside in the Culmination Stage. Finally, in the last stage of interpretation-Aftermathpeople evaluate the transpired event in terms of organizational effects and consequences.

Though Isabella's model has been criticized for being appropriate only for planned events (Barr 1998), we must note that (1) planned events can be rare and unusual, such as the decision to merge with another firm or to launch a major new product, and (2) for unplanned events, where the anticipation stage is bypassed, Isabella's model still explains behavior for the confirmation, culmination, and aftermath stages of interpretation. Both Isabella's (1990) and Barr's (1998) delineation of the temporal dimension of interpretation lends support to Weick's notion that "human situations are progressively clarified" (1995, p. 11). Thus, we chose to incorporate Isabella's (1990) four specific stages of interpretation within our model, as those terms sufficiently capture the temporal similarities across existing process models of interpretation and apply equally as well to rare and unusual events.
Cognitive Biases and Interpretation of Rare Events Organizational interpretation processes are subject to cognitive biases because individuals have limited information processing capacity (March and Simon 1958, Simon 1947) and are selective rather than comprehensive in how they perceive information (Hogarth 1987). People use cognitive heuristics to gain efficiencies when processing information; however, these heuristics often lead to biases (Bazerman 2006, Hogarth 1987). Given the uncertainty that accompanies rare and unusual events, people are likely to rely on convenient heuristics to reduce uncertainty and enable quick action (Hogarth 1987). Thus, because of limited information processing abilities, individuals see what they expect to see and focus on information that is consistent with prior held beliefs or experiences (Fiske and Taylor 1991, Hogarth 1987). Cognitive biases occur throughout the various stages of information processing with some biases more likely at early stages than at late ones (Hogarth 1987). For example, early in interpretation stages as people are acquiring information and making comparisons, heuristics such as selective perception and anchor and adjustment are likely to be a factor. Later, however, biases such as representativeness, framing, and hindsight bias are likely to be influential. ${ }^{2}$ 


\section{Hierarchical Context and Interpretation of Rare Events}

Organizational interpretation processes are also subject to local rationality (Cyert and March 1963) and situated attention (Hoffman and Ocasio 2001, Ocasio 1997). First, organizations, as open systems, are a set of nested subsystems (Ashmos and Huber 1987) or "multi-hierarchical systems" (Van Cauwenbergh and Cool 1982). Each subsystem or level in the system has a local rationality (Cyert and March 1963) and develops its own language and norms that influence what people in the subsystem perceive (Ocasio 2005). For example, top management is the "institutional" subsystem that sets general direction and guides the organization through the environment, and front-line management is the "technical" subsystem that processes materials and provides services to customers (Van Cauwenbergh and Cool 1982). Middle managers form the implementation subsystem and provide linkage between the other two levels (Wooldridge and Floyd 1990). The local rationality created by each subsystem influences how interpretations happen. The organization or the parts of the environment that managers confront situate their attention (Ireland et al. 1987) or distribute it according to function, channels of communication, or procedures (Ocasio 1997). The hierarchical context affects the cues that managers notice (Weick 1995). This context also contributes to competing interpretations between and across hierarchical levels (Milliken et al. 2005).

\section{Stages of Interpretation}

\section{Anticipation Stage-When Rumors Start to Fly}

In the first stage of interpretation-Anticipation-managers sense that something is about to happen, and the interpretive task involves assembling disparate pieces of information into an "in progress" frame of reference, which will shape the understanding of events as they are unfolding (Isabella 1990). The interpretation of the rare event at this stage is vague (Barr 1998); it is in progress because the frame develops as individuals acquire each additional rumor or piece of speculative information. Selective perception is likely to be a major cognitive factor affecting interpretations at the Anticipation Stage, as people often look for rumors and tidbits of information that are consistent with prior held beliefs and that reinforce existing views. ${ }^{3}$ At this stage, middle managers receive rumors and tidbits of information from superiors and upper management that are influenced by the strategic context and information from further down the organization that is influenced by the context of technical or marketplace realities. Because of their location in the organization, they also hear rumors from other middle managers that affect how they consider rare and unusual events in this early stage (Balogun and Johnson 2004).
Anticipation Stage and Rare Events. Standard ways of scanning and observing-at all levels of the organization-are likely to be oriented toward known rather than unknown events. Analysis of the space shuttle Columbia disaster suggests that early warning signals went unheeded, in part because managers at the Johnson Space Center discounted discordant information (concerns from engineers that the foam debris was dangerous). Rather than surfacing the discordant information, managers looked for confirmatory data (there have been many launches in which foam debris did not cause a problem), thereby accumulating bits and pieces of information that confirmed their beliefs (Edmondson et al. 2005). In addition, NASA managers discounted any safety risks resulting from the foam strike and eventually came to view this type of damage as inevitable.

This discounting of risk was compounded by the fragmented, silo-style analysis used to assess the damage to Columbia. Conflicting viewpoints and dissenting opinions thus remained at the local level and were "ineffective in overcoming conventional wisdom about foam strikes" (Edmondson et al. 2005, p. 225). At the Anticipation Stage of interpretation it is easy for managers to notice those cues that reinforce their previously held views of the world, meaning some rare events may be viewed as salient by some managers but not by others. At this stage the rumors and tidbits of information competing for managers' attention may well be in conflict, further complicating how the organization gives meaning to rare events.

Organizations at this stage of interpreting rare and unusual events may display the tendency to try to control the rumors or spread of information, leading to univocal interpretation or what Maitlis (2005) calls restricted sensemaking. When this happens, the desire for control often trumps the need for divergent views, limiting the organization's opportunity for richly experiencing the event. If allowed to play their pivotal role, middle managers can enrich the way the organization experiences the rare and unusual event by championing multiple views, by surfacing rather than silencing rumors, and by exposing rather than consolidating various tidbits of information. Being a champion is one of the behaviors that Floyd and Lane (2000) suggest for middle managers wanting to help bring about strategic renewal.

We suggest that championing divergence and surfacing conflicting views is a role that middle managers can play to enhance learning when the organization faces a rare and unusual event. Middle managers can help the organization experience events richly by giving visibility to the multiple interpretations to which they have access. In this way, they "animate" the interpretation process by intensely exchanging information and encouraging ongoing conversations (Maitlis 2005). For expected or routine events, encouraging such divergence or animation may be too costly for the organization. However, for 
rare and unusual events that bring confusion and ambiguity, bringing conflicting perceptions to the surface can help the organization hear from a broad set of voices and minimize the chance of acting precipitously. Thus, we propose:

Proposition 1. Organizations experience rare and unusual events more richly when, at the Anticipation Stage of interpretation, middle managers surface conflicting rumors and elicit multiple tidbits of information.

\section{Confirmation Stage-What Can We Expect Now?}

In the second stage-Confirmation-an event begins to be experienced and individuals face the interpretive task of standardizing the experience by explaining it (Isabella 1990). They do this by comparing the unfolding event to past events that provide parallel frames of reference, which can be used to create "conventional" explanations. Because people in the organization have different past experiences with which to compare the unfolding events, explanations at this stage will differ. The availability bias is likely to influence interpretations at this stage because people often confuse easy-to-recall past experiences with accurate or relevant past experiences (Bazerman 2006, Hogarth 1987). ${ }^{4}$

When a rare and unusual event begins to unfold, top managers - because of the availability bias-will likely compare the event to their most recent strategic experience while front line managers will likely compare the event to their most recent technical and operational experiences. At the Confirmation Stage of interpretation, middle managers have access to strategic managers' explanations of a rare and unusual event, the more narrow explanations from front-line managers, and the explanations of their peers. These multiple and varied explanations form a "mosaic of conflicting lessons" (March et al. 1991), but only if they are exposed and exchanged.

Confirmation Stage and Rare Events. Interpreting events at the Confirmation Stage is complicated when the events are rare and unusual because of the lack of any relevant history; research also suggests that people are often overconfident in situations where they know the least (Bazerman 2006). Thus, when facing rare and unusual events there is a great likelihood that managers will confidently assume that their experiences with past events will inform the new and unknown event. Milliken and colleagues (2005) offer an example of this from their analysis of the Columbia disaster. They report that on the second day of the flight, video imagery revealed that a piece of foam may have broken off during take-off and struck the wing, but there was no agreement among managers and engineers as to whether that event was significant. Milliken and colleagues (2005) observed that also on Day 2 of the flight, a working group asked for additional imagery of the likely impacted area of the spacecraft. Upper-level managers ignored or denied all requests for these images, largely because they easily recalled past experiences with foam strikes that did not cause failure.

In the Confirmation Stage of interpretation, the explanations that managers offer of rare and unusual events are likely to come from personal experiences. Managers use personal experiences as cognitive starting points for explanations because people are comfortable with their own past experiences. However, using past experience as a referent limits managers' abilities to see new events as rare or unusual and in need of careful attention. The lessons from the Columbia disaster suggest that people near the middle of the organization recognized the need for more information and developed alternate explanations of what might be unfolding. However, these middle managers failed to gain the attention of critical decision makers; those with more organizational power ignored them.

At this stage, middle managers are often privy to numerous explanations of the rare and unusual event as it unfolds. These many explanations are avenues for the organization to experience the pending event more richly. Rather than consolidate or ignore these multiple and likely conflicting explanations, middle managers can help the organization learn by sharing these explanations and encouraging discussion of them (Hoon 2007). In this way, the organization is more likely to "experience more aspects of experience" (March et al. 1991, p. 2); that is, more aspects of the rare and unusual event. Maitlis (2005) referred to such divergence as "fragmented sensemaking" in which leaders do not attempt to control sensemaking. With fragmented sensemaking, multiple views and explanations are allowed to exist, and organizational members across all levels are actively engaged in an "animated" sensemaking process.

During the Confirmation Stage, organizations are more likely to experience events richly when multiple views and explanations of the unfolding event are exposed and multiple members participate in the interpretation process. Middle managers can contribute to this fragmented yet animated sensemaking by aggressively sharing the multiple and possibly conflicting explanations with the strategic and front-line managers with whom they interrelate. If organizations hope to keep from missing signals of rare and unusual events (i.e., learn from past events), it is important that middle managers aggressively share information-a middle management role suggested by Floyd and Lane (2000) and encourage the exchange of possible explanations of what might happen. Thus, we propose:

Proposition 2. Organizations experience rare and unusual events more richly when, at the Confirmation Stage of interpretation, middle managers facilitate the exchange of explanations about what is likely to happen. 


\section{Culmination Stage-Now We Deal with It}

In the third stage-Culmination-there is a sense of before and after. People reconstruct what they knew to be true prior to the event in light of the new event, comparing the old to the new and the past to the present (Isabella 1990). Reconstruction involves determining what behaviors, interactions, and norms from the past are still relevant and which of those needs amending. In this stage, the use of frames (i.e., mental structures through which people view the world) (Russo and Schoemaker 2002, Tversky and Kahneman 1981) is likely to be a cognitive factor affecting interpretation and leading to conflicting understandings. At the Culmination Stage of interpretation, each manager's frame guides how he or she reconstructs his or her world, retaining some understandings and altering others. ${ }^{5}$ At the Culmination Stage, middle managers receive amended explanations from front-line managers, from strategic managers, and from their peers across the organization and face the task of bridging the gap between conflicting explanations of what has happened.

Culmination Stage and Rare Events. The task of interpretation during the Culmination Stage becomes more difficult in the case of rare and unusual events because the past offers few referents for how to consider what has happened to help revise one's explanation. Cognitive heuristics such as framing place further constraints on understanding by narrowing the field of vision. As a result, subsequent action and learning may be fragmented or delayed. In their review of the Columbia disaster, Dunbar and Garud (2005) observed that NASA operated using two conflicting organizing frames-one that emphasized knowledge use in support of exploration and another that emphasized knowledge use in support of task performance.

This dual mode of operating resulted in different perspectives (or frames) of events with different meanings in different parts of the organization. Some groups from the "exploration" mode classified the foam loss as an "out-of-family" event, and others from the "task performance" mode categorized it as an accepted risk. Top management (from the task performance mode) established a low-status team to investigate the meaning of the falling foam but did not give them the authority to acquire needed photos, which could have led to a better amended explanation that integrated multiple views. The dominance of the production or "task performance" mode made it difficult to understand the significance of data that from an "exploration" mode had more significance.

The consequences of this distributed organizational understanding were data indeterminacy (or the inability to assess the significance of available data) and difficulty in deciding on, developing, and initiating a response. Rather than seeking to integrate the explanations offered by the two major modes, top management imposed its explanation on the organization. Dunbar and Garud (2005, p. 216), whose findings underscore the importance of accurate interpretation at the Culmination Stage, quote NASA's Columbia Accident Investigation Board:

Because managers failed to avail themselves of the wide range of expertise and opinion necessary to achieve the best answer to the debris strike question- "Was this a safety-of-flight concern?"-some Space Shuttle program managers failed to fulfill their implicit contract to do whatever is possible to ensure the safety of the crew. In fact, their management techniques unknowingly imposed barriers that kept at bay both engineering concerns and dissenting views, and ultimately helped create "blind spots" that prevented them from seeing the danger the foam strike posed. (Columbia Accident Investigation Board 2003, p. 170)

At the Culmination Stage of interpretation, the event has happened, implementation of response to the event is under way, and people are amending their earlier explanations based on reactions to the event. Because middle managers lead implementation efforts, at this stage it is helpful if the amended explanations of what has happened begin to converge rather than diverge. Divergence early on is important because it generates many possible ways to think about what may occur. Once people experience the rare event and attempt to act, convergence is necessary so that actions can be coherent. People need help understanding why procedures are changing, and middle managers can lead the readjustments and changes by blending the disparate explanations that may still be circulating (Floyd and Lane 2000). Blending involves integrating the various existing views and is not the same as forcing a single interpretation on others.

During this Culmination Stage, it is likely that managers' frames will affect how they amend their interpretation of an event once it has unfolded. Thus, when considering rare events, effective interpretations require managers to incorporate alternate referent points, multiple perspectives, and mechanisms to reconcile differences across the organization in order for action to occur. At this stage, middle managers face the task of blending the amended explanations from those above, beneath, and across the organization. This merging of views supports the development of a consistent perspective, where everyone acts from the same page as response options are considered. Thus, we propose:

Proposition 3. Organizations experience rare and unusual events more richly when, at the Culmination Stage of interpretation, middle managers blend the amended explanations of what has happened.

\section{Aftermath Stage-Looking Back}

In the Aftermath Stage, managers assess responses to the event after enough time has elapsed to consider the existing reality essentially permanent. During this period, 
individual and organizational interpretations include the determination of which parties profited, the recognition of positive and/or negative outcomes, and the overall estimated value to the organization (Isabella 1990). Interpretations at this stage become specific and concrete (Barr 1998). Hindsight bias (Fischoff 1975) is likely to be a cognitive factor affecting interpretations at this stage. Because people distort their beliefs about what they actually knew before an event based on what they learned after the fact (Hogarth 1987), it will be difficult for people to accurately judge the impact of the event. ${ }^{6}$ In this final stage of interpretation, the "linking role" (Wooldridge and Floyd 1990) that middle managers play is critical to how the organization ultimately comes to understand and internalize the rare and unusual event. In the midst of turmoil and uncertainty, top managers often send confusing signals about what behaviors and understandings they expect (Burgelman 1983, Floyd and Lane 2000, Kanter 1982). Thus, middle managers are the recipients of after-the-fact understandings from those above, beneath, and across the organization, which may well be competing (Milliken et al. 2005).

Aftermath Stage and Rare Events. As with the preceding stages, the ability to correctly interpret events during the Aftermath Stage requires more effort when these events are rare and unusual. Managers may reflect on events that initially appeared inconceivable but are now considered reasonable, given the passage of time and knowledge of outcomes. Unfortunately, when managers incorporate this perspective, the opportunities for accurate assessment and effective learning diminish. In his study of NASA's history preceding the Columbia disaster, Farjoun (2005) found that NASA and the space shuttle program missed learning opportunities from similar prior mission failures. He observed that learning lessons from the 1999 failure of two robotic Mars probes "had not been fully internalized" (Farjoun 2005, p. 75) across the organization. The factors that impeded "organizational learning" included incomplete reviews caused by time, scheduling, and resource pressures and a predominate silo mentality based on space program and field center identities. In addition, NASA officials did not capture useful lessons learned because of their inability to see the future relevance of the Mars probe incidents, in effect finding no connection between robotic and manned space programs. NASA further stifled learning chances by "decoupling...the groups that recommend lessons and the groups that implement them" (Farjoun 2005, p. 75), thereby limiting the flow of potentially useful information.

How, then, do managers learn from rare and unusual events when they rely on cognitive heuristics, such as hindsight bias, that convert the relevant to the irrelevant, the unlikely to the typical, and the implausible to the ordinary? Woods (2005) suggests that improved learning more likely occurs when a "quasi-independent group" bridges the gaps between organizational units and develops a "complete and coherent view of the...event" (p. 299). At this stage, organizations evaluate the effects and implications from the rare event just experienced. Important to this evaluation function is considering the lessons learned for the organization as a whole. Middle managers, because they bridge the strategic and operational levels, can capture important lessons learned from all levels.

We therefore submit that middle managers can perform this important role during the Aftermath Stage by combining the evaluations received from those above, beneath, and across the organization; categorizing these evaluations as important or not, as unusual or normal; and getting the attention of others in the organization for their evaluations. In doing so, middle managers "synthesize" (Floyd and Lane 2000) the multiple lessons learned into a unitary, though rich, account (Maitlis 2005). They then can communicate this integrated view outward so others receive access to the collective learning. Thus, we propose:

Proposition 4. Organizations experience rare and unusual events more richly when, at the Aftermath Stage of interpretation, middle managers synthesize the evaluations of what has happened.

\section{Conclusion}

Given the complex and rapidly changing nature of most organizational environments, rare and unusual events are likely to challenge organizations at an ever-increasing pace. Making sense of these events, identifying cues, and giving them meaning is a prerequisite for learning and for action. More than two decades ago, Daft and Weick (1984) described organizations as interpretation systems, where interpretation is a critical component of how organizations learn. Since their seminal article, we have come to understand more about how top managers are likely to interpret events (Barr 1998, Thomas et al. 1993), yet we still have little knowledge of what it means for organizations to develop interpretations. Although most studies acknowledge the "socially constructed" nature of interpretations, little is known about the multilevel pattern of interactions that take place to create the organization's overall interpretation. What is an organization's interpretation? Who forms the organization's interpretation? These questions are important, as much of the analyses of the Columbia disaster suggest that faulty interpretation systems played a role in what happened.

In this paper, we argue that in the case of rare and unusual events, the interpretation stage of learning takes on heightened importance because, by definition, a rare and unusual event is associated with surprise and being taken unawares (Cunha et al. 2006). Thus, when they are 
confronted by rare and unusual events, people search for a way to interpret what has happened, and these interpretations play a key role in determining what can be learned from the event (Daft and Weick 1984, Lant et al. 1992, March et al. 1991).

Building on the work of earlier interpretation scholars, such as Isabella (1990) and Barr (1998), we offer a multilevel, multistage model of organizational interpretation that illuminates the complexity created by cognitive biases and hierarchical context. These elements affect how meaning is imparted to rare and unusual events. Our model is also based on the theoretical assumption that interpretation is a process of creating meaning (Gioia and Chittipeddi 1991) rather than being a process of distributing meaning. Our exploration of how organizations interpret rare and unusual events builds on prior work that highlights the important role that middle managers play in sensemaking in general (Balogun 2003; Balogun and Johnson 2004, 2005). Here we suggest that (1) organizations can develop a rich interpretation at each stage of interpreting a rare and unusual event, in spite of cognitive biases, and (2) middle managers, because of their position in the hierarchy, participate in multiple conversations that can help shape the organization's interpretation.

A more active role for middle managers in interpretation contributes to learning from rare and unusual events in four ways. First, as we highlighted previously, March and colleagues remind us that organizations learn from small samples when they experience rare and unusual events richly, and this involves three activities. One, an organization learns from a rare event when its members experience more and different aspects of the event as the event occurs. Two, an organization learns more from a rare event if its members exchange interpretations about what is happening. Three, organizational learning from a rare event occurs when varying perceptions of likely outcomes and multiple preferences for outcomes are considered (March et al. 1991). Middle managers can help organizations learn different lessons from rare events because of their structural proximity to so many different individuals, who attach unique meaning to the same experience (March et al. 1991). However, the responsibility for richly experiencing rare events falls on top management, which needs to encourage middle managers to be vigilant sensemakers and sensegivers (Maitlis 2005).

The second reason that an active role for middle managers in interpretation contributes to learning from rare and unusual events relates to the fact that the interpretation of ambiguous data is not always a straightforward process. As Milliken and colleagues (2005) noted, "Well-intentioned people sitting in different places in an organization can see the same stimulus differently" (p. 251). We propose that interpretation benefits maximally from the multiple contexts-top, middle, and front line-in which multiple managers notice stimuli and form interpretations. As Huber (1991) suggests, more and varied interpretations translate to more learning.

Third, considerable evidence suggests that managers' perceptions are often not accurate (Mezias and Starbuck 2003, Starbuck and Hedberg 2001). We argue that it is less likely that any one "misperception" will dominate an organization's interpretation of a rare and unusual event when the organization considers and shares multiple interpretations, thereby improving the reliability of the learning process (March et al. 1991). Because cognitive biases affect every manager's interpretation of events, it is less likely that any one cognitive bias will dominate the interpretation because, in a sense, the cognitive biases of one group counteract those of another group. The result is improved organizational understanding, and consequently a more valid learning process (March et al. 1991).

Fourth, organizations can avoid catastrophic errors through mindful organizing that resists simplification (Weick and Sutcliffe 2001). When top managers hold middle managers responsible for both animating and guiding the interpretation process, a more complex process of interpretation unfolds and the organization resembles the mindful organizing that Weick (2005) calls for:

People who engage in mindful organizing regard simplification as a threat to effectiveness. They pay attention to information that disconfirms their expectations and thwarts desires. To do this they make a deliberate effort to maintain a more complex, nuanced perception of unfolding events. Labels and categories are continually reworked, received wisdom is treated with skepticism, checks and balances are monitored, and multiple perspectives are valued. (p. 168)

When organizations use a robust organizational interpretation system in which middle managers assume an active role, they are more likely to experience rare and unusual events richly, increasing the chance of learning from such events. We began this paper by highlighting some of the most common difficulties people have in noticing and reacting to rare and unusual events. They have a tendency to ignore warnings that are inconsistent with their own beliefs (Nystrom and Starbuck 1984) and to normalize that which is not normal (Vaughan 2005). People also have a tendency to downplay the likelihood of ambiguous threats (Edmondson et al. 2005, Goleman 1985).

The central argument of this paper is that when middle managers take an active role in the interpretation of rare and unusual events, chances that the organization will avoid the mistakes of ignoring warnings, normalizing that which is not normal, and downplaying ambiguous threats increase. When middle managers both animate and guide the process of interpretation, multiple perspectives will be represented and will shape the meaning 
Figure 1 The Role Middle Managers Perform in Organizational Interpretation and Learning from Rare and Unusual Events

\begin{tabular}{|c|c|}
\hline \multicolumn{2}{|c|}{ Middle manager behaviors across stages of interpretation of rare and unusual events } \\
\hline $\begin{array}{cc}\text { Anticipation } & \text { Confirmation } \\
\text { Behaviors that encourage divergence }\end{array}$ & $\begin{array}{l}\text { Culmination Aftermath } \\
\text { Behaviors that encourage convergence }\end{array}$ \\
\hline $\begin{array}{l}\text { - Sensemaking (Maitlis 2005) } \\
\text { - Championing divergent views (Floyd and } \\
\text { Lane 2000) } \\
\text { - Animating (Maitlis 2005) } \\
\text { - Surfacing/exposing conflicting views } \\
\text { - Disseminating/sharing information } \\
\text { (Mintzberg 1978) }\end{array}$ & $\begin{array}{l}\text { - Sensegiving (Maitlis 2005) } \\
\text { - Linking (Floyd and Wooldridge 1992) } \\
\text { - Integrating/blending (Nonaka 1988) } \\
\text { - Guiding adaptation (Chakravarthy 1982) } \\
\text { - Synthesizing (Floyd and Lane 2000) } \\
\text { - Selling (Dutton and Ashford 1993) }\end{array}$ \\
\hline \multicolumn{2}{|c|}{ Impact on organizational interpretation of rare and unusual events } \\
\hline $\begin{array}{l}\text { - Realize a broader set of interpretations } \\
\text { (Huber 1991, March et al. 1991) } \\
\text { - Incorporate a diversity of viewpoints (Fiol } \\
\text { 1994) } \\
\text { - Reduced likelihood of } \\
\text { ○ Normalizing unusual events (Vaughan 2005) } \\
\text { Ignoring warnings inconsistent with beliefs } \\
\text { (Nystrom and Starbuck 1984) } \\
\text { Downplaying ambiguous threats } \\
\text { (Edmondson et al. 2005) }\end{array}$ & $\begin{array}{l}\text { - Experience events more richly (March } \\
\text { et al. 1991) } \\
\text { - Allow for emergent interpretation } \\
\text { (Milliken et al. 2005, Plowman and } \\
\text { Duchon 2008) } \\
\text { - Not dominated by any one bias (Bazerman } \\
\text { 2006, Hogarth 1987) } \\
\text { - Establish narratives (Abma 2000, Boje } \\
\text { 1995, Fincham 2002) }\end{array}$ \\
\hline \multicolumn{2}{|c|}{ Impact on organizational learning from rare and unusual events } \\
\hline $\begin{array}{r}\text { Increases learning } \\
\text { Learn different lessons } \\
\text { Increases reliability and vali } \\
\text { Mindful organizing }\end{array}$ & $\begin{array}{l}\text { ber 1991) } \\
\text { rch et al. 1991) } \\
\text { (March et al. 1991) } \\
\text { eick 2005) }\end{array}$ \\
\hline
\end{tabular}

that is given to rare or unusual events. At each stage of interpretation, it is more likely that the organization can experience the rare event richly, and thereby increase its capacity to learn from the event, when middle managers actively animate and guide interpretations.

Similarly, when organizations encourage an active sensemaking (animating) and sensegiving (guiding) role for middle managers, there is no single or dominant interpreter in all situations. Rather, our model as shown in Figure 1, recognizes that managers at all levels of the organization interpret issues and discourages the practice of dictating a dominant interpretation from the top down. Instead, in our model we give attention first to exposing differences among interpretations, then allowing for and integrating these multiple interpretations. Through the activities of blending and synthesizing (Floyd and Lane 2000), middle managers contribute to a dynamic process of interpretation in which multiple filters from throughout the organization help frame and enrich interpretations of rare and unusual events. The interpretation becomes more like a mosaic of multiple understandings. The dominant concerns of strategic managers and front-line managers are woven into this interpretation mosaic.

\section{Limitations}

We rely heavily on the empirical findings of Isabella (1990) and Barr (1998), who each observed that interpretation happens in distinct stages and recognized there is an assumed linearity and rigidity to the model that is probably not always accurate (Brown and Humphreys 2003). The distinct stages that Isabella observed may be a function of her focus on the interpretation of large-scale organizational change. The model we present implies a linear relationship and a unitary sequential movement from one stage to another. Consider, for example, the likely stages of interpreting an unusual event such as the detection of a foam strike against the wing of a space shuttle: the event occurred, there was no Anticipation Stage, and an initial interpretation task was to 
decide whether the event was significant. Although some at NASA were sure that a significant event had occurred and were immediately in the Confirmation Stage, comparing this event to other past events and perhaps moving quickly to the Culmination Stage, others failed to attend to the foam strike until the re-entry disintegration of Columbia 16 days later. Thus, it is possible that the organization does not move in a unitary or rigid fashion through the stages, as implied by Isabella, especially when there is not agreement as to whether there is an event under consideration. This line of research could benefit from the empirical examination of interpretation in other types of events besides organizational change.

We additionally make extensive and exclusive use of secondary literature regarding the space shuttle Columbia disaster to provide examples that support our theory development. We did not develop our theory based on these examples. Even so, we recognize the limitations of using this specific rare and unusual event as a reference point. NASA is a very particular kind of organization. Thus, the middle management experience there may not be entirely representative of other middle management experiences.

We also recognize the potential limits to the generalizability of our model. We have constrained our model to include three concepts related to learning from rare and unusual events - the temporal sequence of the related interpretation process, cognitive biases, and hierarchical context. However, other concepts have the potential to influence our model as well. For example, power differentials between the hierarchical levels in organizations may hamper the sharing of information and interpretations and thus limit the chance for middle managers to guide and animate the interpretation process. Such power struggles were evident in the Columbia disaster. Managers at NASA often overruled the lower-level engineers who struggled to gain attention for their safety concerns (Buljan and Shapira 2005). This conflict grew, in part, from the pressures on managers to meet launch schedules. Similarly, power differences across levels could potentially modify the cognitive processes of the organization. Lant and Shapira (2001) suggest that institutional barriers, such as power structures and control mechanisms, may inhibit how organizations store and use information. These barriers can result in faulty interpretations and performance assessments. Incorporation of additional concepts, such as power, could expand the generalizability of our model by accounting for further direct and moderating effects on organizational learning from rare and unusual events. In addition, rare events are often sudden and require a rapid response that allows little time for socially constructed processes. Situational demands may require that organizations act based on factors other than interpretations. Further research into options to abbreviate or condense our model's stages could prove useful for these acute situations.

\section{Implications for Research}

Although we focused largely on how middle managers can influence the vertical exchange of information and meaning related to rare and unusual events, it is clear that middle managers also influence each other (Balogun 2003; Balogun and Johnson 2004, 2005). Middle managers are part of a social network of players who shape how organizations come to understand and give meaning to cues and signals. It is through their interaction with others across all levels that interpretations form and knowledge creation and understanding occur (Nonaka 1994). Consideration of the social dynamics in the formation of interpretations could further our understanding of how organizations interpret and learn from rare events. In one sense, we have argued here that much of the organizational literature on interpretation takes a narrow view-strategic managers form interpretations and dispense them, much as if they were a commodity, to others. In fact, the process may often be much more complex, and conceptualizing organizations as social networks that change constantly (Kilduff et al. 2006) could provide an even richer way of considering the complex nature of organizational interpretation.

Because of the topic of this special issue, our paper focuses on how organizations make sense of rare and unusual events. However, sensemaking and interpretations are clearly part of the everyday experience of participating in an organization. A useful line of research would be to examine the differences in everyday sensemaking and sensemaking that occurs in rare and unusual events. Do organizations that encourage the use of multiple voices for sensemaking in everyday situations perform better in rare and unusual events than those that are more efficient in everyday sensemaking? Do these organizations tend to be surprised less often? Many of the research questions we have suggested are best addressed through qualitative research methods, such as the use of narratives (Czarniawska 1998), that will help researchers continue to build theory related to organizational interpretation.

Finally, there is some evidence that organizations that devote attention to how they manage meaning outperform those who only emphasize how they manage information (Sutcliffe and Weber 2003). Thus, an organization's "interpretation orientation" has the potential to be a source of competitive advantage. Organizations can learn and from learning, can perform better. A strong role for middle managers in shaping the organization's interpretation of events and situations may be critical in developing an interpretation orientation that becomes a strategic advantage, not just in the case of rare and unusual events.

\section{Implications for Practice}

In a world of accelerating change, increasing complexity, and ongoing uncertainty, attention to how people make sense of rare and unusual events becomes more 
important for organizations. The illustrations from the space shuttle Columbia disaster provide vivid examples of how easily organizations can drift into routine ways of noticing events and standardized ways of interpreting events that can be extremely costly, if not catastrophic.

At least three implications for managers emerge from the elaboration of our model. First, many managers avoid conflict and even see the presence of conflict as a managerial weakness. However, experiencing rare and unusual events richly, and thereby learning from them, requires conflicting perceptions and interpretations. Multiple interpretations do not necessarily mean incoherence; they may be a sign of an organization in the process of a rich experience.

Second, managers should be encouraged and rewarded for asking questions that do not confirm biases and for seeking out disparate views. It is by surfacing divergent thinking that managers can best see their way forward in ambiguous situations. This will not happen, though, if organizations dismiss conflict and fault managers for its presence. Middle managers who raise conflicting views about an impending event or who facilitate the exchange of explanations about unfolding events may be helping the organization experience the unfolding event richly.

Finally, our model emphasizes an active role for middle managers in shaping the way organizations interpret rare and unusual events. This may require changes in entrenched practices that do not yield easily. Much of the analysis of the Columbia disaster points to a rigid organizational culture more inclined to accept the judgments of those high in the organization than those with expertise, whose interpretations might have made a difference (Starbuck and Farjoun 2005).

Interpretation is one of the key components of organizational learning. If organizations learn from rare and unusual events, it happens in part because their interpretation processes enable them to experience events richly. Our theory of organizational interpretation reveals the complexity of this process by illuminating the temporal, cognitive, and hierarchical dimensions of interpretation. At every stage of the interpretation process, cognitive bias and organizational hierarchy are likely to influence the interpretations that are given to rare and unusual events. Middle managers, however, are in a unique position to help organizations experience unfolding events richly by encouraging divergence in the early stages of interpretation and convergence in later stages. In the face of rare and unusual events and moments of complete ambiguity, organizations that have developed interpretation systems that broaden rather than limit the number of interpretations are better equipped to respond effectively to the future that is unfolding around them.

\section{Acknowledgments}

The authors would like to thank Dennis Duchon for his insightful comments and careful editing that improved the quality of this paper. They also thank Cynthia Lengnick-Hall, Reuben McDaniel, Lynn Isabella, Mukta Kulkarni, and Leticia Andrade for their helpful comments on earlier versions of this paper. The authors express their appreciation to the editors of the special issue and three anonymous Organization Science reviewers who helped them significantly improve their arguments.

\section{Endnotes}

${ }^{1}$ On February 1, 2003, the space shuttle Columbia broke apart during re-entry when a hole in the shuttle's left wing became compromised. A piece of foam from the external fuel tank detached, struck Columbia's left wing during the shuttle launch, and caused the hole. In an effort to understand the behavioral and organizational factors that led to the disaster, Starbuck and Farjoun (2005) invited and combined research contributions from several organization scholars. We drew heavily from their book and collective insights as the source for our examples.

${ }^{2}$ Hogarth (1987) organized a list of 29 cognitive biases by stages of information processing in which each bias is most likely to occur: acquisition, processing, output, and feedback. During the acquisition stage, biases such as selective perception, concrete information, and data effects are some of the biases most likely to occur. During the processing stage, biases such as anchoring and adjusting, representativeness, and others are likely to occur. In the output stage, biases such as framing, illusion of control, and wishful thinking are likely. Finally, in the feedback stage, biases such as hindsight bias, confirmation trap, and attribution errors are most likely to occur. These information-processing stages seemed to us to parallel Isabella's (1990) stages of interpretation. Thus, we draw on Hogarth's framework in elaborating our model of organizational interpretation and highlight one likely bias at each stage of the interpretation process.

${ }^{3}$ Based on Hogarth's (1987) information stages, other biases such as frequency and illusory correlation also affect how people accumulate rumors and bits of information.

${ }^{4}$ Other biases that may occur at this stage include representativeness (Bazerman 2006), and anchoring and adjusting.

${ }^{5}$ Other biases that could affect managers at this stage in amending their earlier explanations include illusion of control (people exaggerate the extent to which they control things, self-aggrandizing when the outcomes are good and rationalizing when outcomes are bad) and wishful thinking (people's preferences for outcomes of events affect their assessment of the events) (Hogarth 1987).

${ }^{6}$ Other biases that are also likely at this stage of the interpretation process include the fallacies in recall (Hogarth 1987), which is the finding that the inability to recall details of an event leads to erroneous reconstruction of events; and attribution error, which is the tendency to attribute the success of an outcome to one's skill and the failure of an outcome to chance.

\section{References}

Abma, T. A. 2000. Fostering learning-in-organizing through narration: Questioning myths and stimulating multiplicity in two performing art schools. Eur. J. Work Organ. Psych. 9(2) 211-231.

Ansoff, H. I. 1975. Managing strategic surprise by response to weak signals. California Management Rev. 18 21-33. 
Ashmos, D. P., G. P. Huber. 1987. The systems paradigm in organization theory: Correcting the record and suggesting the future. Acad. Management Rev. 12(4) 607-622.

Bazerman, H. M. 2006. Judgment in Managerial Decision Making. John Wiley \& Sons, Hoboken, NJ.

Balogun, J. 2003. From blaming the middle to harnessing its potential: Creating change intermediaries. British J. Management 14 69-83.

Balogun, J. 2006. Managing change: Steering a course between intended strategies and unanticipated outcomes. Long Range Planning 39 29-49.

Balogun, J., G. Johnson. 2004. Organizational restructuring and middle manager sensemaking. Acad. Management J. 47(4) 523-549.

Balogun, J., G. Johnson. 2005. From unintended strategies to unintended outcomes: The impact of change recipient sensemaking. Organ. Stud. 26(11) 1573-1601.

Barr, P. S. 1998. Adapting to unfamiliar environmental events: A look at the evolution of interpretation and its role in strategic change. Organ. Sci. 9(6) 644-669.

Bazerman, M. H. 2006. Judgment in Managerial Decision Making. John Wiley \& Sons, Hoboken, NJ.

Boje, D. 1995. Stories of the storytelling organization: A postmodern analysis of Disney as "Tamara-Land." Acad. Management J. 38(4) 997-1035.

Brooks, I. 1997. Call my bluff: Multiple interpretations of an organizational process. British J. Management 8 269-282.

Brown, A. D., M. Humphreys. 2003. Epic and tragic tales: Making sense of change. J. Appl. Behavioral Sci. 39(2) 121-144.

Buljan, A., Z. Shapira. 2005. Attention to production schedule and safety as determinants of risk-taking in NASA's decision to launch the Columbia shuttle. W. H. Starbuck, M. Farjoun, eds. Organization at the Limit: Lessons from the Columbia Disaster. Blackwell Publishing, Oxford, UK, 140-156.

Burgelman, R. A. 1983. A process model of internal corporate venturing in the diversified major firm. Admin. Sci. Quart. 28 223-244.

Chakravarthy, B. S. 1982. Adaptation: A promising metaphor for strategic management. Acad. Management Rev. 7 35-44.

Columbia Accident Investigation Board. 2003. Report, 6 vols.: Vol. 1, http://caib1.nasa.gov/news/report/volume1/; Vol. 6, http://caib1. nasa.gov/news/report/volume6/. Government Printing Office, Washington, DC.

Cunha, M. P., S. R. Clegg, K. Kamoche. 2006. Surprises in management and organization: Concept, sources and a typology. British J. Management 17 317-329.

Cyert, R. M., J. G. March. 1963. A Behavioral Theory of the Firm. Prentice-Hall, Englewood Cliffs, NJ.

Czarniawska, B. 1998. A Narrative Approach in Organizational Studies. Sage Publications, Thousand Oaks, CA.

Daft, R. L., K. E. Weick. 1984. Toward a model of organizations as interpretation systems. Acad. Management Rev. 9(2) 284-295.

Day, G. S., P. J. H. Schoemaker. 2004. Driving through the fog: Managing at the edge. Long Range Planning 37 127-142.

Dunbar, R., R. Garud. 2005. Data indeterminacy: One NASA, two modes. W. H. Starbuck, M. Farjoun, eds. Organization at the Limit: Lessons from the Columbia Disaster. Blackwell Publishing, Oxford, UK, 202-219.

Dutton, J. E., S. J. Ashford. 1993. Selling issues to top management. Acad. Management Rev. 18(3) 397-428.
Dutton, J. E., S. E. Jackson. 1987. Categorizing strategic issues: Links to organizational action. Acad. Management Rev. 12 76-90.

Dutton, J. E., S. J. Ashford, R. M. O’Neill, E. Hayes, E. E. Wierba. 1997. Reading the wind: How middle managers assess the context for selling issues to top managers. Strategic Management $J$. 18(5) 407-425.

Edmondson, A. C., M. A. Roberto, R. M. J. Bohmer, E. M. Ferlins, L. R. Feldman. 2005. The recovery window: Organizational learning following ambiguous threats. W. H. Starbuck, M. Farjoun, eds. Organization at the Limit: Lessons from the Columbia Disaster. Blackwell Publishing, Oxford, UK, 220-245.

Farjoun, M. 2005. History and policy at the space shuttle program. W. H. Starbuck, M. Farjoun, eds. Organization at the Limit: Lessons from the Columbia Disaster. Blackwell Publishing, Oxford, UK, 21-40.

Fincham, R. 2002. Narratives of success and failure in systems development. British J. Management 13(1) 1-14.

Fiol, C. M. 1994. Consensus, diversity, and learning in organizations. Organ. Sci. 5(3) 403-420.

Fischoff, B. 1975. Hindsight foresight: The effect of outcome knowledge on judgment under uncertainty. J. Experiment. Psych.: Human Perception Performance 1 288-299.

Fiske, S. T., S. E. Taylor. 1991. Social Cognition, 2nd ed. McGrawHill, New York.

Floyd, S. W., P. J. Lane. 2000. Strategizing throughout the organization: Managing role conflict in strategic renewal. Acad. Management Rev. 25(1) 154-177.

Floyd, S. W., B. Wooldridge. 1992. Middle management involvement in strategy and its association with strategic type. Strategic Management J. 13 153-167.

Gioia, D. A., K. Chittipeddi. 1991. Sensemaking and sensegiving in strategic change initiation. Strategic Management J. 12(6) 433-448.

Gioia, D. A., J. B. Thomas. 1996. Identity, image, and issue interpretation: Sensemaking during strategic change in academia. Admin. Sci. Quart. 41(3) 370-403.

Golden, B. R., J. M. Dukerich, F. H. Fabian. 2000. The interpretation and resolution of resource allocation issues in professional organizations: A critical examination of the professional-manager dichotomy. J. Management Stud. 37(8) 1157-1187.

Goleman, D. 1985. Vital Lies, Simple Truths: The Psychology of SelfDeception. Simon \& Schuster, New York.

Hodgkinson, G. P., P. R. Sparrow. 2002. The Competent Organization: A Psychological Analysis of the Strategic Management Process. Open University Press, Philadelphia.

Hoffman, A. J., W. Ocasio. 2001. Not all events are attended equally: Toward a middle-range theory of industry attention to external events. Organ. Sci. 12(4) 414-434.

Hogarth, R. 1987. Judgment and Choice, 2nd ed. John Wiley \& Sons, New York.

Hoon, C. 2007. Committees as strategic practice: The role of strategic conversation in a public administration. Human Relations $\mathbf{6 0}$ 921-952.

Huber, G. P. 1991. Organizational learning: The contributing processes and the literatures. Organ. Sci. 2(1) 88-115.

Huy, Q. N. 2002. Emotional balancing of organizational continuity and radical change: The contribution of middle managers. Admin. Sci. Quart. 47(1) 31-69. 
Ireland, R. D., M. A. Hitt, R. A. Bettis, D. A. de Porras. 1987. Strategy formulation processes: Differences in perceptions of strength and weaknesses indicators and environmental uncertainty by managerial level. Strategic Management J. 8(5) $469-485$.

Isabella, L. A. 1990. Evolving interpretations as a change unfolds: How managers construe key organizational events. Acad. Management J. 33(1) 7-41.

Kanter, R. M. 1982. The middle manager as innovator. Harvard Bus. Rev. (July-August) 150-161.

Kauffman, S. 1995. At Home in the Universe. Oxford University Press, New York.

Kilduff, M., W. Tsai, R. Hanke. 2006. A paradigm too far? A dynamic stability reconsideration of the social network research program. Acad. Management Rev. 31(4) 1031-1048.

Klein, K. J., S. W. J. Kozlowski. 2000. Multilevel Theory, Research, and Methods in Organizations: Foundations, Extensions, and New Directions. Jossey-Bass, San Francisco.

Lampel, J., Z. Shapira. 2001. Judgmental errors, interactive norms, and the difficulty of detecting strategic surprises. Organ. Sci. 12(5) 599-611.

Lant, T. K., Z. Shapira. 2001. New research directions on organizational cognition. T. K. Lant, Z. Shapira, eds. Organizational Cognition: Computation and Interpretation. Lawrence Erlbaum Associates, Mahwah, NJ, 367-376.

Lant, T. K., F. J. Milliken, B. Batra. 1992. The role of managerial learning and interpretation in strategic persistence and reorientation: An empirical exploration. Strategic Management J. 13 585-608.

Levitt, B., J. G. March. 1988. Organizational learning. Annual Rev. Sociol. 14 319-340.

Levy, D. 1994. Chaos theory and strategy: Theory, application, and managerial implications. Strategic Management J. 15 167-178.

Maitlis, S. 2005. The social processes of organizational sensemaking. Acad. Management J. 48(1) 21-49.

Majchrzak, A., S. L. Jarvenpaa, A. B. Hollingshead. 2007. Coordinating expertise among emergent groups responding to disasters. Organ. Sci. 18(1) 147-161.

March, J. G., H. A. Simon. 1958. Organizations. John Wiley, New York.

March, J. G., L. Sproull, M. Tamuz. 1991. Learning from samples of one or fewer. Organ. Sci. 2(1) 1-13.

Martins, L. L., A. Kambil. 1999. Looking back and thinking ahead: Effects of prior success on managers' interpretations of new information technologies. Acad. Management J. 42(6) 652-661.

McDaniel, R. R., M. E. Jorday, B. F. Fleeman. 2003. Surprise, surprise, surprise! A complexity science view of the unexpected. Health Care Management Rev. 28(3) 266-278.

Meyer, A. D. 1982. Adapting to environmental jolts. Admin. Sci. Quart. 12 515-537.

Mezias, J. M., W. H. Starbuck. 2003. Studying the accuracy of managers' perceptions: A research odyssey. British J. Management 14 3-17.

Milliken, F. J. 1990. Perceiving and interpreting environmental change: An examination of college administrators' interpretation of changing demographics. Acad. Management J. 33(1) 42-63.
Milliken, F. J., T. K. Lant, E. N. Bridwell-Mitchell. 2005. Barriers to the interpretation and diffusion of information about potential problems in organizations: Lessons from the space shuttle Columbia. W. H. Starbuck, M. Farjoun, eds. Organization at the Limit: Lessons from the Columbia Disaster. Blackwell Publishing, Oxford, UK, 246-266.

Mintzberg, H. 1978. Patterns in strategy formation. Management Sci. 24(9) 934-948.

Nonaka, I. 1988. Toward middle-up-down management: Accelerating information creating. Sloan Management Rev. 29(3) 9-18.

Nonaka, I. 1994. A dynamic theory of organizational knowledge creation. Organ. Sci. 5(1) 14-37.

Nystrom, P. C., W. H. Starbuck. 1984. To avoid organizational crises, unlearn. Organ. Dynam. 12(4) 53-65.

Ocasio, W. 1997. Towards an attention-based view of the firm. Strategic Management J. 18(6) 187-206.

Ocasio, W. 2005. The opacity of risk: Language and the culture of safety in NASA's space shuttle program. W. H. Starbuck, M. Farjoun, eds. Organization at the Limit: Lessons from the Columbia Disaster. Blackwell Publishing, Oxford, UK, 101-121.

Park, K. M. 2007. Antecedents of convergence and divergence in strategic positioning: The effects of performance and aspiration on the direction of strategic change. Organ. Sci. 18(3) 386-402.

Plowman, D. A., D. Duchon. 2008. Emergent leadership: Getting beyond heroes and scapegoats. J. Hazy, J. Goldstein, B. Lichtenstein, eds. Complex Systems Leadership Theory (CSLT). ISCE Publishing Company, Mansfield, MA, 124-142.

Plowman, D. A., L. T. Baker, T. E. Beck, M. Kulkarni, S. T. Solansky, D. V. Travis. 2007. Radical change accidentally: The emergence and amplification of small change. Acad. Management J. 50(3) 515-543.

Rothman, J., V. J. Friedman. 2001. Identity, conflict and organizational learning. M. Dierkes, A. B. Antal, J. Child, I. Nonaka, eds. Handbook of Organizational Learning and Knowledge. Oxford University Press, New York, 582-597.

Rouleau, L. 2005. Micro-practices of strategic sensemaking and sensegiving: How middle managers interpret and sell change every day. J. Management Stud. 42(7) 1413-1441.

Russo, J. E., P. J. H. Schoemaker. 2002. Winning Decisions: Getting It Right the First Time. Currency, New York.

Schwab, A. 2007. Incremental organizational learning from multilevel information sources: Evidence for cross-level interactions. Organ. Sci. 18(2) 233-251.

Schwenk, C. R. 1984. Cognitive simplification processes in strategic decision making. Strategic Management J. 5 111-128.

Senge, P., C. O. Scharmer, J. Jaworski, B. S. Flowers. 2004. Presence: An Exploration of Profound Change in People, Organizations, and Society. Doubleday, New York.

Senge, P. M. 1990. The Fifth Discipline. Doubleday/Currency, New York.

Sharma, S. 2000. Managerial interpretations and organizational context as predictors of corporate choice of environmental strategy. Acad. Management J. 43(4) 681-697.

Shaw, B. 1903. Man and Superman. The University Press, Cambridge, MA.

Simon, H. A. 1947. Administrative Behavior: A Study of DecisionMaking Processes in Administrative Organizations. MacMillan, New York. 
Sims, D. 2003. Between the millstones: A narrative account of the vulnerability of middle managers' storying. Human Relations 56(10) 1195-1211.

Starbuck, W. H., M. Farjoun, eds. 2005. Organization at the Limit: Lessons from the Columbia Disaster. Blackwell Publishing, Oxford, UK.

Starbuck, W. H., B. Hedberg. 2001. How organizations learn from success and failure. M. Dierkes, A. B. Antal, J. Child, I. Nonaka, eds. Handbook of Organizational Learning and Knowledge. Oxford University Press, New York, 327-350.

Sutcliffe, K. M., K. Weber. 2003. The high cost of knowledge. Harvard Bus. Rev. (May) 74-82.

Thomas, J. B., R. R. McDaniel, Jr. 1990. Interpreting strategic issues: Effects of strategy and the information-processing structure of top management teams. Acad. Management J. 33 286-306.

Thomas, J. B., S. M. Clark, D. A. Gioia. 1993. Strategic sensemaking and organizational performance: Linkages among scanning, interpretation, action, and outcomes. Acad. Management J. 36(2) 239-270.

Thomas, J. B., L. J. Shankster, J. E. Mathieu. 1994. Antecedents to organizational issue interpretation: The roles of single-level, cross-level, and content cues. Acad. Management J. 37(5) $1252-1284$.

Tversky, A., D. Kahneman. 1981. The framing of decisions and the rationality of choice. Science 185 1124-1131.

Van Cauwenbergh, A., K. Cool. 1982. Strategic management in a new framework. Strategic Management J. 3 245-264.
Vaughan, D. 2005. System effects: On slippery slopes, repeating negative patterns, and learning from mistake? W. H. Starbuck, M. Farjoun, eds. Organization at the Limit: Lessons from the Columbia Disaster. Blackwell Publishing, Oxford, UK, 41-59.

Watkins, M. D., M. H. Bazerman. 2003. Predictable surprises: The disasters you should have seen coming. Harvard Bus. Rev. 81(3) 72-80.

Weick, K. E. 1993. The collapse of sensemaking in organizations: The Mann Gulch disaster. Admin. Sci. Quart. 38 628-652.

Weick, K. E. 1995. Sensemaking in Organizations. Sage Publications, Thousand Oaks, CA.

Weick, K. E. 2005. Making sense of blurred images: Mindful organizing in Mission STS-107. W. H. Starbuck, M. Farjoun, eds. Organization at the Limit: Lessons from the Columbia Disaster. Blackwell Publishing, Oxford, UK, 159-177.

Weick, K. E., K. M. Sutcliffe. 2001. Managing the Unexpected: Assuring High Performance in an Age of Complexity. JosseyBass, San Francisco.

Wissema, H. 2002. Driving through red lights: How warning signals are missed or ignored. Long Range Planning 35(25) 521-539.

Woods, D. D. 2005. Creating foresight: Lessons for enhancing resilience from Columbia. W. H. Starbuck, M. Farjoun, eds. Organization at the Limit: Lessons from the Columbia Disaster. Blackwell Publishing, Oxford, UK, 289-308.

Wooldridge, B., S. W. Floyd. 1990. The strategy process, middle management involvement, and organizational performance. Strategic Management J. 11 231-241. 